\title{
AUDIT SISTEM INFORMASI PADA CALL CENTER PADA PT ARGA BANGUN BANGSA (ESQ LEAERSHIP CENTER) DENGAN MENGGUNAKAN FRAMEWORK COBIT
}

\author{
Universitas Mitra Indonesia, Sistem Informasi \\ khoiriazulhijah.students@umitra.ac.id
}

\begin{abstract}
ABSTRAK
Call center ESQ merupakan aplikasi berbasis web yang digunakan oleh tim telemarketing, tim

telecorporate, finance, dan BM (Branch Manager) untuk menjalankan fungsi bisnis ESQ LC. Data sudah menjadi aset penting dalam perusahaan untuk mengantisipasi hal-hal yang tidak diinginkan berkaitan dengan penyalahgunaan data maka harus dilakukan audit. Pentingnya informasi, maka kebijakan tentang keamanan sistem merupakan salah satu aspek yang sangat penting dalam sebuah sistem informasi. Audit Sistem Informasi menjadi

sebuah solusi untuk mengukur sejauh mana selama ini sistem call center melakukan proses DS5 dan DS11 agar ESQ LC dapat melakukan perbaikan-perbaikan. IT (Information Technology) Governance merupakan struktur

hubungan dan proses untuk mengarahkan dan mengendalikan organisasi untuk mencapai tujuannya dengan menambahkan nilai ketika menyeimbangkan risiko dibandingkan dengan TI dan prosesnya. Kerangka kerja COBIT

(Control Objective For Information and Related Technology) versi 4.1, dimana COBIT mempunyai tujuan untuk mengendalikan TI terkait dan merupakan suatu standar yang telah diakui cukup baik pada tingkat internasional.

Dalam penelitian ini membahas 1 domain yaitu Deliver and Support dari 4 domain yang ada di COBIT dengan

pembahasan dibatasi pada tingkat control process pengelolaan data (DS11) dan memastikan keamanan sistem

(DS5) untuk management awareness dan maturity level. Hasil dari audit sistem informasi adalah tingkat kinerja

proses DS5 (memastikan keamananan sistem) dan DS11 (pengelolaan data) adalah sedang. Maturiy Level DS5 dan

DS11 saat ini (as is) ada pada level 3 kondisi di mana perusahaan telah memiliki prosedur standar formal dan
\end{abstract}


tertulis yang telah disosialisasikan ke segenap jajaran manajemen dan karyawan untuk dipatuhi dan dikerjakan

dalam aktivitas sehari-hari tapi kurang ada pengawasan untuk menjalankan itu semua. Dan (to be) yang

diharapkan menunjukkan level 4 perusahaan memiliki indikator sebagai sasaran terhadap kinerja proses TI serta

terdapat fasilitas untuk memonitor dan mengukur prosedur yang sudah berjalan. Rekomendasi ke level 4 IT

Governance ini dibuat guna meningkatkan kinerja call center di ESQ LC.

Usulan Performance Indicator dan

Outcome Measure diharapkan dapat diterapkan agar proses TI tercapai sesuai dengan tujuan yang diharapkan

dalam DS5 dan DS11.

Kata Kunci: Audit, call center, IT Governance, Activities dan IT Goals, COBIT. 


\section{A. PENDAHULUAN}

Perkembangan teknologi yang semakin cepat telah membawa dunia memasuki era baru khususnya dibidang informasi dan bahkan lebih cepat dari yang pernah dibayangkan sebelumnya. Sistem Informasi merupakan aset bagi suatu perusahaan yang bila diterapkan dengan baik akan memberikan kelebihan untuk berkompetensi sekaligus meningkatkan kemungkinan bagi kesuksesan suatu usaha (Maniah dan Kridanto 2005). PT. Arga Bangun Bangsa (ESQ LC) saat ini merupakan salah satu lembaga pelatihan sumber daya manusia terbesar di Indonesia. Dalam sebulan terselenggara rata-rata 100 even training di dalam Dalam hal sumber daya manusia, ESQ LC kini didukung lebih dari 500 orang karyawan.

Call center yang baik adalah call center yang mudah dihubungi, cepat, akurat, profesioanal dan mampu menangani pelanggan dengan baik. Data yang besar dibutuhkan pengelolaan yang baik agar mendapatkan output yang diharapkan. Memastikan keamanan sistem sangat penting untuk mengetahui kemungkinan penyalahgunaan aktivitas terkait dengan TI yang kritis di perusahaan. Untuk mengantisipasi dampak yang mungkin terjadi karena sistem tidak dapat diandalkan maka harus dilakukan audit terhadap sistem call center. Hasilnya dapat digunakan sebagai dasar untuk melakukan langkahlangkah luas untuk memecahkan masalah yang mungkin terjadi dimasa yang akan datang. 


\section{B. TINJAUAN PUSTAKA} Pengertian Sistem Informasi Menurut pendapat Jogiyanto (2001) bahwa sistem informasi adalah suatu sistem di dalam suatu .

organisasi yang mempertemukan

kebutuhan pengolahan transaksi harian, mendukung operasi, bersifat manajerial dan kegiatan strategis dari suatu organisasi dan menyediakan pihak luar tertentu dengan laporan-laporan yang dibutuhkan.

\section{Pengertian Audit Sistem Informasi}

Audit SI memberikan evaluasi yang bersifat independen atas kebijakan, prosedur, standar, pengukuran, dan praktik untuk menjaga/mencegah informasi yang bersifat elektronik dari kehilangan, kerusakan, penelusuran yang tidak disengaja dan

sebagainya (NSAA \& GAO, 2011). Audit SI secara

umum mencakup hal-hal sebagai berikut: meninjau

lingkungan dan fisik, administrasi sistem, software

aplikasi, keamanan jaringan, kontinuitas bisnis, dan integritas data (Gondodiyoto \& Hendarti, 2006).

\section{Tujuan Audit SI}

Tujuan audit sistem informasi untuk meninjau dan memberikan umpan balik, menjamin dan melakukan rekomendasi mengenai tiga hal sebagai

berikut ketersediaan (availability), kerahasiaan

(Confidentiality) dan integritas.

Detail tentang tujuan audit sistem informasi

dijelaskan (Gondodiyoto \& Hendarti, 2006)

sebagai

berikut:

1. Untuk mengidentifikasi sistem yang ada baik maupun yang digunakan menyeluruh.

2. Untuk dapat lebih memahami seberapa besar

sistem informasi mendukung kebutuhan strategis

perusahaan, operasi perusahaan, mendukung

kegiatan operasional departemen/unit/divisi,

kelompok kerja maupun para petugas dalam

melaksanakan kegiatannya.

3. Untuk mengetahui pada bidang atau area mana, fungsi, kegiatan atau business process yang didukung dengan sistem serta teknologi informasi yang ada

4. Untuk menganalisis tingkat pentingnya data/informasi yang dihasilkan oleh sistem dalam rangka mendukung kebutuhan para pemakainya. antara sistem dan kebutuhan

5. pengolahan dan transfer informasi

6. Untuk mengidentifikasi apakan ada kesenjangan antara sistem dan kebutuhan.

7. Untuk membuat peta dari alur informasi yang ada. 


\section{STUDI KASUS}

Arsitektur Call Center

Call center merupakan aplikasi

berbasis web yang di gunakan oleh tim telemarketing, tim telecorporate,

finance, dan BM ( Branch

Manager ) untuk menjalankan fungsi bisnis sesuai dengan tanggung jawabnya. 9 orang jumlah BM ( Branch Manager ). Jumlah telecorporate dan telemarketing ada 150

orang baik yang dipusat ataupun di cabang. Ada 12 agent call center yang melakukan call/day.

Ada 2 server yang digunakan untuk mengolah

data lokal (jakarta) dan cabang

(daerah). Server untuk

mengolah data lokal terdapat di

ESQ LC pondok

pinang sedangkan server untuk

menangani data

daerah terdapat di gedung cyber yang terletak di Jl.

Kuningan Barat No. 8 Jakarta Selatan. Jaringan yang

digunakan adalah Firstmedia. Untuk kontrol akses

keamanannya menggunakan firewall.

\section{Proses Bisnis Call center}

Proses bisnis call center dimulai

ketika agent call

center melakukan call berdasarkan

data pribadi, data

alumni peserta training, data

referensi dari alumni.

Telemarketing sama dengan agent call center

menggunakan call center untuk call dan registrasi

peserta yang akan mengikuti training. Telecorporate

menggunakan sistem call center

untuk registrasi

peserta training. Finance untuk memvalidasi

pembayaran training dan BM

(Branch Manager)

untuk monitoring banyaknya peserta yang mengikuti

training dan banyaknya jumlah

call/day yang di call

oleh tim telemarketing.

\section{Analisis Audit \\ Analisis Identifikasi Responden \\ Dengan analisis identifikasi \\ responden yang \\ mengacu pada diagram RACI \\ tersebut, maka \\ sampling atau identifikasi responden \\ diarahkan pada \\ peran-peran yang terkait langsung \\ dan representatif pada proses \\ DS5.dan DS11}

keamanan sistem adalah baik

Secara umum rekapitulasi hasil

kuesioner I

management awareness untuk DS5

dapat ditarik

suatu kecenderungan yang

merefleksikan fakta di

lapangan yaitu:

1. Sebagian besar responden,

$\mathbf{5 5 , 7 7 \%}$ responden

menyatakan pendapat, opini atau

kesadarannya

bahwa tingkat kinerja dalam

memastikan

keamanan sistem adalah cukup

atau sedang.

2. Sebanyak $\mathbf{3 8 , 4 6 \%}$ responden

mengemukakan

pendapatnya bahwa kinerja

dalam memastikan

keamanan sistem adalah baik.

3. Hanya $5,77 \%$ responden yang Secara umum interpretasi terhadap hasil

kuesioner adalah cukup atau sedang dalam proses

pengelolaan data. Namun harus

ditingkatkan lagi agar

tidak menjadi suatu kerentanan

(vulnerability) bagi

Beberapa ancaman (threat) yang

mengancam

keberadaan data sebagai aset

perusahaan. Ancaman akan

berdampak pada ganguan operasional

maupun memerlukan waktu,tenaga,

dan biaya pemulihannya. 


\section{DISKUSI}

Tentukan hasil dari management awareness

Hasil dari management Awareness menunjukan tingkat kinerja proses DS5 (Memastikan keamanan sistem) dan DS11 (Pengolahan data) adalah sedang

Dengan analisis identifikasi yang mengacu pada diagram RACI maka

sampling atau identifikasi responde pada

peran-peran yang terkait langsung representatif

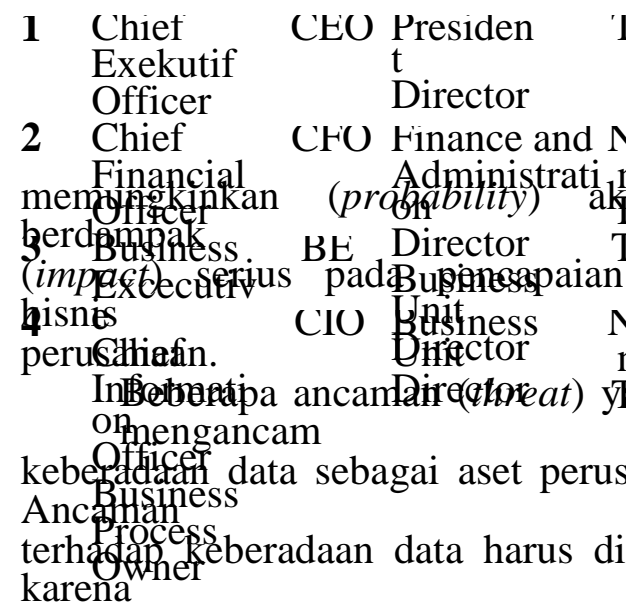




\section{E. KESIMPULAN}

1. Maturiy Level DS5 dan DS11 saat ini (as is) ada pada level 3 yang artinya kondisi di manaperusahaan telah memiliki prosedur standar formal dan tertulis yang telah disosialisasikan ke segenap jajaran manajemen dan karyawan

2. untuk dipatuhi dan dikerjakan dalam aktivitassehari-hari namun namun kurang ada keamanaan sistem 
F. REFRENSI

[1] PUTRA, Arie Setya; FEBRIANI, Ochi Marshella. Knowledge Management Online Application in PDAM Lampung Province. In: Prosiding International conference on Information Technology and Business (ICITB). 2018. P. 181-187.

[2] FEBRIANI, Ochi Marshella; PUTRA, Arie Setya. Sistem Informasi Monitoring Inventori Barang Pada Balai Riset Standardisasi Industri Bandar Lampung. Jurnal Informatika, 2014, 13.1: 90-98

[3] Putra, A. S. (2018, July 9). 2018 Artikel Struktur Data , Audit dan Jaringan Komputer. Retrieved from osf.io/3uq8w

Jogiyanto. 2008. Metodologi

Penelitian Sistem

Informasi. Yogyakarta: Penerbit ANDI.

[ITGI] Information Technologi

Governance Institute

207 COBIT 4.1 Edition: Audit

Guidelines, IT Governance

Institute.

Illinois: ITGI.

Maniah \& Surendro Kridanto. 2005.

Usulan model audit sistem informasi studi kasus sistem 
